ISSN 0717 - 2877

Universidad de Talca - Facultad de Ciencias Jurídicas y Sociales

El derecho administrativo sancionador y los sectores de referencia en el sistema institucional chileno

Luis Cordero Vega

Trabajo recibido el 8 de marzo de 2019 y aprobado el 25 de julio de 2019

\title{
El derecho administrativo sancionador y los sectores de referencia en el sistema institucional chileno
}

REGULATION OF ADMINISTRATIVE SANCTIONS AND REFERENCE AREAS IN THE CHILEAN INSTITUTIONAL SYSTEM

LUIS CORDERO VEGA*

\author{
RESUMEN
}

El Derecho Administrativo Sancionador en Chile ha sido objeto de un intenso debate en la última década, como consecuencia de una progresiva jurisprudencia judicial, constitucional y administrativa que encontró su justificación en el denominado ius puniendi estatal. Sin embargo, paralelamente el Congreso aprobó leyes que desde los sectores de referencia y en ausencia de una regulación general, fueron estableciendo criterios normativos para legitimar la potestad sancionatoria, pero esta vez pensando en el correcto funcionamiento de los ámbitos en donde deben operar los organismos administrativos. Así, esos "sectores testigo" están siendo determinantes en la identificación de los elementos básicos o comunes que debe cumplir la Administración Pública al momento de sancionar.

\section{ABSTRACT}

The regulation of administrative sanctions in Chile has been a subject of intense debate within the last decade, as a result of judicial case law, constitutional jurisprudence and administrative pronouncements that usually have found its justification in the so-called state's "ius puniendi". However, in parallel Congress has passed laws in different reference areas that, despite the absence of a general regulation, were able to establish normative criteria to legitimate sanctioning power, but with the aim of setting up the correct functioning of the spheres where administrative bodies must operate. Thus, these "witness sectors" are being decisive in the identification of the basic or common elements Public Administration must respect when imposing a sanction.

PALABRAS CLAVE

Derecho administrativo, Derecho Administrativo Sancionador, Sectores de referencia.

KEY WORDS

Administrative law, Administrative sanctions, reference areas.

\section{El debate general}

\subsection{El contexto en donde se inserta la discusión del Derecho Administrativo Sancionador}

La discusión del Derecho Administrativo Sancionador se ha tomado parte del debate del Derecho Público nacional en la última década1 ${ }^{1}$. Desde que el Tribunal Constitucional ("TC") en 2006 desechara el requerimiento de inaplicabilidad de las empresas eléctricas sobre la base de un denominado ius puniendi matizado ${ }^{2}$ - haciéndose cargo del precedente en la modificación a la Ley

\footnotetext{
* Doctor en Derecho. Profesor de Derecho Administrativo, Universidad de Chile. Pío Nono 1, Providencia, Santiago, Chile, Icordero@derecho.uchile.cl. Este artículo forma parte del Proyecto Fondecyt Regular № 1161741.

${ }^{1}$ Ver en este sentido los trabajos sistematizadores de CORDERO (2014); LETELIER (2017); ARANCIBIA Y ALARCÓN (2014).

2 Tribunal Constitucional, Rol № 479, de 8 de agosto de 2006 y Tribunal Constitucional, Rol № 480, de 13 de abril de 2006.
} 
de Caza en $1996^{3}$ - , en donde sostuvo la procedencia de aplicar los principios del orden penal, adecuándolos a la gestión de los organismos públicos, se desataron un conjunto de discusiones doctrinales. El propio TC siguió modelando esa aproximación, la que tuvo una cierta consistencia con la jurisprudencia de la Corte Suprema y de la Contraloría General de la República (“Contraloría") 4 .

Esto evidenció la tensión de dos maneras de comprender el Derecho Administrativo nacional. Por una parte, desde una perspectiva de orden meramente potestativo, unilateral y cuidadoso de los derechos individuales, por lo que el Derecho Administrativo Sancionador debe ser entendido como un régimen de garantías que limite el poder de castigo de la Administración. Por la otra, desde una perspectiva que aprecia la sanción administrativa como parte del set de herramientas con que cuenta la Administración para garantizar los objetivos de interés público, de modo que trasladar pura y simplemente la categoría del ius puniendi afecta el contenido mismo de la gestión pública ${ }^{5}$.

Sin embargo, esta discusión en el Derecho Administrativo chileno, como explicaré, se ha realizado al margen de una teoría global del Derecho Administrativo, sin la existencia de una regla general que regule las sanciones administrativas y sobre la base de criterios sustraídos sin referencia específica de su origen. Todo esto ha sucedido en el contexto de sanciones consagradas en sectores específicos, que se han aplicado sobre la base de las reglas sectoriales y en donde ha sido la jurisprudencia quien ha tratado de construir una categoría general.

Por otra parte, desde 2003, de un modo sistemático, además de la doctrina y la jurisprudencia, el legislador progresivamente fue estableciendo criterios normativos para el ejercicio de las potestades sancionadoras de la Administración, realizando en ocasiones un ejercicio de homologación de reglas entre distintos sectores.

De este modo, han sido las regulaciones sectoriales de los últimos años las que han permitido la construcción, además de la jurisprudencia, de lo que podríamos denominar las bases de una teoría general de las sanciones administrativas en el Derecho Administrativo chileno. Mientras hemos puesto gran atención a la manera en cómo los jueces han decidido, poco hemos dicho sobre los estándares que en el mismo período la ley ha ido configurando.

En el Derecho Administrativo regularmente se ha abordado convencionalmente las relaciones entre la parte general y la parte especial como dos estructuras geométricas en donde la primera absorbe la segunda. Se suele indicar pedagógicamente que en la primera se encuentra los criterios ordenadores de las categorías aplicables en donde están "los conceptos, principios, normas e instituciones" que se representan en leyes generales aplicables a la totalidad de la Administración Pública, dejando la parte especial a "los sectores concretos de la actividad administrativa" ${ }^{6}$. Esa es una distinción clásica también en la literatura del Derecho Administrativo chileno ${ }^{7}$ y comparado ${ }^{8}$.

Esa manera clásica de ver el Derecho Administrativo ha impedido que la teoría general considere en sus explicaciones las dinámicas que se producen en la denominada parte especial, impidiendo ver las soluciones y categorías que se desarrollan en dicho lugar y que están explicando el moderno Derecho Administrativo.

\footnotetext{
${ }^{3}$ Tribunal Constitucional, Rol № 244, de 6 de agosto de 1996.

${ }^{4}$ CORDERO (2015), pp. 496-499.

${ }^{5}$ MONTT (2011), p. 74.

${ }^{6}$ REBOLLO Y VERA (2016), p. 32.

${ }^{7}$ SILVA (2009), pp. 51-57.

${ }^{8}$ SEERDEN (2018), pp. 418-436.
} 
Desde finales del siglo XX un sector de la doctrina comparada ha sostenido que las nuevas demandas por intervenciones públicas y la sofisticación de los instrumentos que se exigen, requieren apreciar esos ámbitos bajo otra lógica: a esto se denomina los "sectores de referencia". Estos corresponden a "aquellos sectores del Derecho Administrativo especial que proporcionan un conjunto de materiales y modelos, de casos singulares y de ejemplos, de particular utilidad para la inducción y la construcción de la teoría general" ${ }^{9}$. Es la tarea de realizar el análisis jurídico entre el plano de la intuición (provocada por la sectorialización) con la capacidad de asociación (que se requiere para una explicación general $)^{10}$.

Por tal motivo, como acertadamente ha indicado Parejo, "la tarea pendiente es la selección y la sistematización de los sectores 'testigos' al servicio de la comprobación de la teoría general y, en su caso, como referencia para la actualización de ésta"11.

Para comprender entonces cómo es posible que los sectores de referencia estén contribuyendo al desarrollo de una teoría general de las sanciones en Chile, es conveniente realizar un breve análisis sobre las tensiones que ha estado viviendo el Derecho Administrativo.

\subsection{Las tensiones en el Derecho Administrativo}

Uno de los debates recientes en la literatura del Derecho Administrativo ha estado asociado a su crisis de identidad, en parte vinculado con el hecho de tratar de encontrar una explicación sistémica a su objeto de análisis (la Administración Pública) y sus criterios de actuación, cuando estos han ido variando sustancialmente en los últimos años ${ }^{12}$. Como explicó hace algunos años Sunstein, el cambio desde la teoría de la "forma de gobierno" a la del "gobierno burocrático" exige reformar e interpretar el Derecho Administrativo del modo más fiel posible a los compromisos constitucionales iniciales ${ }^{13}$. El punto es, que ese mundo ha ido transformándose vertiginosamente y es razonable esperar que lo siga haciendo con mayor celeridad en los próximos años.

Pero esta no es la primera crisis de identidad del Derecho Administrativo. El siglo XX lo vivió primero con la teoría del servicio público y la participación privada en los mismos, la reconfiguración del sistema de derechos y luego el debate sobre el Estado regulador, que ha supuesto reconocer un rol protagónico en la "implementación de realidades" a la Administración Pública, dejando al Congreso como habilitador normativo general para la adecuación de distintos espacios o esferas reguladas ${ }^{14}$, lo que ha exigido reformular el estudio del Derecho Administrativo desde los sectores de referencia ${ }^{15}$. Eso dio origen a lo que se denomina el "movimiento de reforma al Derecho Administrativo" que entiende a esta disciplina desde la perspectiva de la dirección, en donde el Derecho Administrativo proporciona un programa de conducta y no un simple modelo de control, como lo entendió el viejo Derecho Público ${ }^{16}$.

Esto ha obligado, en los tradicionales sistemas de Derecho Administrativo, a una adecuación de los elementos clásicos que permitieron la construcción de sus principales instituciones, como la comprensión del contencioso administrativo (el rol del juez administrativo y sus tipologías), la teoría

\footnotetext{
${ }_{9}^{9}$ SCHMIDT-ASSMAN (2003) p.12; PAREJO (2012), p. 399; BARNES (2011), p. 37; WAHL (2013), p. 139; VELASCO (2014), p. 76.

${ }^{10}$ SCHMIDT-ASSMAN (2012), p. 83.

11 PAREJO (2012), p. 598.

12 VERMULE (2016), pp.1-22.; ROSE-ACKERMAN Y LINDSETH (2010), p. 1-2; PAREJO (2012), pp. 385-396.

${ }^{13}$ SUNSTEIN (1993), pp. 227-232.

${ }^{14}$ CASSESE (2012), pp. 603-604; (2014), p. 449.

${ }^{15}$ SCHMIDT-ASSMANN (2003), pp. 128-130; BARNES (2011), pp. 37-38.

${ }^{16}$ WAHL (2013), p. 139; PAREJO (2012), p. 496; BARNES (2011), p. 10.
} 
del acto y del procedimiento administrativo, la organización administrativa, la función pública y el Derecho Administrativo Sancionador, entre otras. Esa tensión - generada por una inevitable innovación estatal y una indispensable adecuación normativa - ha permitido buscar criterios de identidad para tratar de orientar a un "Derecho Administrativo extraviado" ${ }^{17}$ en sus categorías dogmáticas habituales.

Mientras ese debate se encuentra abierto en otras realidades, el problema central del Derecho Administrativo chileno es que hace tiempo viene tratando de encontrar su identidad. Chile, a diferencia de lo que sucedió en los sistemas comparados, carecía y aún carece de un modelo general de resolución de controversias contenciosas administrativas que permitiera delimitar las instituciones tradicionales (sanciones administrativas, responsabilidad del Estado, acto, procedimiento y contrato administrativo), tardíamente dictó una Ley de Procedimiento Administrativo ${ }^{18}$ y ha estado marcado intensamente por un modelo de control público externo en manos de la Contraloría (institución que no tiene equivalente comparado en competencias, que define los alcances de la legalidad a través de la toma de razón y la comprensión del Derecho que aplica la Administración mediante sus dictámenes).

De ahí, que tanto para la doctrina como para la jurisprudencia tradicional los sacrificios dogmáticos de qué corresponde a cada institución han sido escasamente considerados en nuestro medio. El Derecho Administrativo construido tras el golpe militar de 1973 y la Constitución de 1980, enterró el pasado de un Derecho Público de instituciones y lo transformó en un mecanismo de control de potestades para garantizar "derechos" naturales ${ }^{19}$. En ese momento, lo importante era establecer un sistema de control judicial estricto de la discrecionalidad, dar "certeza jurídica" a través de la teoría de los "derechos adquiridos", reprendiendo constitucionalmente cualquier propósito de expansión de la intervención pública ${ }^{20}$ y controlando férreamente los poderes sancionatorios de la Administración, amparándose para ello en las "garantías del orden penal"21.

Ese sistema simple no responde a las demandas de sociedades democráticas modernas y la resolución compleja de problemas públicos. La denominada transformación del Derecho Administrativo en uno de regulación adaptativa, hace sencillamente imposible concebir un sistema reducido a la ecuación "control-derechos" 22 . La necesidad de atender los problemas sociales de la modernidad se tradujo en un conjunto de reformas legales que desde 1990 cambiaron el rostro de la intervención administrativa y rediseñaron la organización estatal, lo que exigió a la jurisprudencia constitucional, judicial y administrativa la modelación progresiva, a ratos con un retraso de más de cincuenta años en términos comparados, de las instituciones esenciales del Derecho Administrativo nacional. Eso es en parte lo que subyace a la forma en como hemos debatido en el último tiempo sobre el Derecho Administrativo Sancionador ${ }^{23}$.

\subsection{La importancia de la última década en el Derecho Administrativo chileno: la época de oro}

Habitualmente el lenguaje popular utiliza la expresión la "época de oro" para referirse a un período de tiempo en el que una actividad, la sociedad o un momento de la historia tienen una

\footnotetext{
17 PAREJO (2012), p. 492.

${ }^{18}$ Ley № 19.880 , de 2003.

${ }^{19}$ FERRADA (2005), p. 104.

${ }^{20}$ PANTOJA (1996), p. 161.

${ }^{21}$ LETELIER (2017), p. 622.

22 BARNES (2011), p. 26.

${ }^{23}$ MONTT (2011), p. 74
} 
etapa de esplendor, en donde se desarrollan cuestiones esenciales para el objeto de que se trate. Esto es lo que ha sucedido con el Derecho Administrativo chileno de la última década.

Dos son las razones que me permiten sostener esta afirmación. La primera, es que durante este período la densidad normativa de esta disciplina avanzó sustancialmente con la dictación de leyes como las de procedimiento administrativo $(2003)^{24}$, compras públicas $(2003)^{25}$ y acceso a la información pública (2009) ${ }^{26}$, lo que provocó la necesidad de dar estructura dogmática a elementos normativos, que con anterioridad se habían escondido en "argumentos de autoridad". La segunda, porque en esta última década como nunca antes, los tres organismos que han actuado como "jueces administrativos" (la tercera sala de la Corte Suprema, el TC y la Contraloría) estuvieron integrados o encabezadas por especialistas de la disciplina ${ }^{27}$. La conjugación de estos dos factores ha implicado que en estos años el Derecho Administrativo chileno - por la vía jurisprudencial- hubiese tratado de construir un marco que le ha dado sentido a muchas de sus instituciones y entre ellas a las sanciones administrativas.

A principios de los 90 el Derecho Administrativo chileno había olvidado las raíces sobre las cuales se construyó antes del golpe militar de 1973, esto es: la teoría del servicio público, la organización administrativa, el empleo y el control público. Estás fueron consideradas parte de un pasado sospechoso o al menos desconocido ${ }^{28}$, por su preferencia "estatista". La influencia de una visión "personalista" del Derecho Público y la prescindencia de la regulación pública para comprender sus relaciones jurídicas, era de algún modo la explicación que había logrado consolidarse desde los 80. Los argumentos del profesor Eduardo Soto Kloss habían terminado de imponerse para una importante cantidad de estudiantes, académicos y jueces. La tesis predominante en nuestro sistema administrativo se basaba en argumentos que limitaban o negaban la autotutela administrativa y en que se reprochaban los títulos públicos para "afectar" derechos de los particulares en cualquier circunstancia sobre la base de la idea de protección de "derechos adquiridos"; esto suponía negar la invalidación administrativa (porque representaba la autotutela), aceptar la nulidad de derecho público de pleno derecho (insubsanable e imprescriptible), un sistema de responsabilidad del Estado estricto (acción constitucional e imprescriptible que corrige desequilibrios en el ejercicio del poder) y utilizar el sistema de derechos fundamentales a través del recurso de protección como una acción contenciosa administrativa de nulidad ${ }^{29}$.

Además de esa consolidación conceptual, a principios de los 90 el Derecho Administrativo estaba tratando de restructurar en parte su contenido por una pretensión unificadora del mismo sobre la base de la dictación de la Ley de Bases Generales de la Administración del Estado ${ }^{30}$ en 1986 que, como se sabe, no fue sino el reconocimiento de la pretensión de unidad que la jurisprudencia de Contraloría venía reclamando desde los años $60^{31}$. Este asunto no es menor, porque salvo el

\footnotetext{
${ }^{24}$ Ley № 19.880 , de 2003.

${ }^{25}$ Ley № 19.886, de 2003.

${ }^{26}$ Ley № 20.285, de 2008.

${ }^{27}$ En el caso de la Corte Suprema el año 1998 se integró Urbano Marín y en el año 2006 lo hizo Pedro Pierry. En el caso de la Contraloría General de la República en 2007 asumió Ramiro Mendoza y en 2016 lo hizo Jorge Bermúdez. En el Tribunal Constitucional en 2009 se integró Carlos Carmona, el 2012 Domingo Hernández y el 2013 Iván Aróstica. Todos ellos reconocidos especialistas y profesores de Derecho Administrativo.

${ }^{28}$ SOTO (1996), pp. 21-34.

${ }^{29}$ FERRADA (2005), p. 104-106.

${ }^{30}$ Ley № 18.575, de 1986.

${ }^{31}$ PANTOJA (1986), pp. 3-12.
} 
Estatuto Administrativo ${ }^{32}$, esta ley fue la primera que trataba de establecer la existencia de un régimen jurídico común en la Administración Pública.

Esto tuvo importantes consecuencias en el Derecho Administrativo chileno, porque frente a su escasa densidad legal -corregida parcialmente desde 2003 como se indicó- y la inexistencia de un sistema unificado de lo contencioso administrativo, transformó a instituciones como el recurso de protección en la Corte Suprema, la solicitud de dictaminación en la Contraloría y la inaplicabilidad en el TC luego de la reforma constitucional del 2005, en los desarrolladores jurisprudenciales del Derecho Administrativo chileno ${ }^{33}$.

En efecto, es el desarrollo jurisprudencial de la última década el que ha permitido ir consolidando progresivamente esta disciplina. ¿Por qué esta cuestión es relevante? Por la manera en que tradicionalmente entendemos el rol del "juez administrativo" en la construcción del Derecho Administrativo. Como se ha indicado, el Derecho Administrativo no está codificado, pero sobre todo es en buena medida un Derecho no legislado o en donde solo existen enunciados generales que permiten la intervención pública y que legitiman determinado tipo de decisiones. La consecuencia de esto es que, en Derecho Administrativo, las normas más importantes han sido históricamente enunciadas por quien ejerce la función de "juez administrativo". La renuencia para aplicar las reglas del Derecho común y la gran cantidad de lagunas legislativas, algunas conscientes y otras inconscientes, ha llevado a quien ejerce esa función, por vía jurisprudencial, a la determinación y aplicación de principios que han construido el Derecho Administrativo ${ }^{34}$.

Es en ese contexto es que se desarrolló "nuestra" teoría del Derecho Administrativo Sancionador.

\section{La construcción nacional del Derecho Administrativo Sancionador}

\subsection{La intuición doctrinaria y su manifestación jurisprudencial en el ius puniendi estatal}

Como era de esperar tras la configuración de los 80 , la discusión nacional original en materia de Derecho Administrativo Sancionador se centró en si resultaba constitucionalmente legítimo que la Administración pudiese ejercer potestades sancionatorias. Ello, por cuanto, en opinión de la doctrina predominante por algunos años, solo los tribunales de justicia podían aplicar sanciones. Así, se indicaba que

(...) desde los albores de la República, las sanciones administrativas cargan a cuestas el peso de su inconstitucionalidad (...) Y si "en caso alguno", o sea nunca el Primer mandatario y, por extensión natural, los demás órganos de la Administración dependientes de él o relacionados con él, pueden poseer competencia al efecto, como quiera que el Código Fundamental rechaza la intromisión de una autoridad administrativa en la esfera del quehacer judicial, resulta en concreto que no puede ninguna ley facultarlos para hacer acreedores de penas o sanciones a los presuntos infractores del ordenamiento jurídico ${ }^{35}$.

En el mismo sentido, otros consideraban que dado que la Carta Fundamental prohibía al Presidente de la República ejercer funciones de juez, tampoco resultaba pertinente que el legislador

\footnotetext{
${ }^{32}$ Ley № 18.884 , de 1989.

${ }^{33}$ CORDERO (2016), p. 396.

${ }^{34}$ VEDEL (1980), pp. 45-46; CORDERO (2016), pp. 393-397.

${ }^{35}$ ARÓSTICA (1991), p. 174.
} 
otorgara a órganos de la Administración la potestad para sancionar a particulares, señalado al efecto que aquello

(...) aparece directamente violatorio de sus preceptos y en consecuencia esas disposiciones legales son abiertamente inconstitucionales, sino que además infringen garantías y derechos fundamentales de las personas, a cuyo servicio, como órgano del Estado que son el legislador y los órganos de la Administración, ellos están por imperativo constitucional (artículo $1^{\circ}$ inciso $\left.4^{\circ}\right)^{36}$.

La discusión en ese momento se focalizó en la naturaleza jurisdiccional que debía o no ostentar la aplicación de una sanción administrativa. Los autores reconocieron que

(...) la actividad del legislador chileno en los últimos años (1988-1993) ha estado marcada por una oscilación o vaivén entre 1.1) devolver a los jueces esa capacidad que constitucionalmente les pertenece de castigar las infracciones a los diferentes ordenamientos jurídicos, y 1.2) una tendencia, quizás mayoritaria, de fortalecer la capacidad sancionadora de la Administración, incluso la legislación ex post marzo de 1990, con Congreso y todo ${ }^{37}$.

Por su parte, la doctrina comparada, según se explicaba en nuestro país, refiriéndose a la relación existente entre las penas penales y las penas administrativas, distinguía dos posturas: por un lado, aquellos que consideraban que los dos tipos de sanciones se diferenciaban por la naturaleza misma de las infracciones a las cuales se imponían, de manera que la sanción penal y la administrativa eran cualitativamente distintas y, por la otra, aquellos que consideraban que entre los ilícitos penales y administrativos, solo existía un matiz gradual, por lo que estos solo se distinguían cuantitativamente ${ }^{38}$.

En particular, la doctrina penal nacional sostuvo que

(...) la diferencia entre el ilícito gubernativo (administrativo) y el penal es exclusivamente cuantitativa. Entre ambos, en efecto, sólo puede hacerse una distinción de magnitudes. El administrativo no es sino un injusto de significación ético-social reducida, que por tal razón sólo debe estar sometido a sanciones leves cuya imposición no requiere garantías tan severas como las que rodean a la de la pena penal ${ }^{39}$,

pero que en todo caso la denominación "pena" de la Constitución debía entenderse como un criterio amplio de ilícito - el ius puniendi- que justificaría las garantías constitucionales provenientes del № 3 del artículo 19 de la Carta Fundamental ${ }^{40}$.

Transcurrido el tiempo y constatada la existencia de diversas normas que otorgaban potestades sancionatorias a los órganos de la Administración, el debate público comenzó a girar en torno a que la sanción administrativa proviene del denominado ius puniendi estatal y, en tal sentido, le eran aplicables a ella y al procedimiento que le sirve de base - con matices - las garantías provenientes del Derecho Penal ${ }^{41}$.

La tendencia jurisprudencial, según algunos autores se tradujo en

\footnotetext{
${ }^{36}$ SOTO (2012), p. 495. La cursiva es del original.

${ }^{37}$ ARÓSTICA (1991), p. 176.

${ }^{38}$ CURY (1988), p. 74.

${ }^{39}$ CURY (1988), p. 76. La cursiva es del original.

${ }^{40}$ RODRÍGUEZ (1987), p. 128.

${ }^{41}$ CORDERO (2015), p. 494.
} 
(...) trasplantar al orden sancionador administrativo todas las garantías procesales (racional y justo procedimiento previo, presunción de inocencia, audiencia, etc.) y principios (tipicidad, antijuridicidad, culpabilidad, etc.) propios del derecho penal, porque parecen haber notado nuestros jueces que es menester imprimir una mínima coherencia al derecho penal administrativo, el que no encontrándose codificado con una imprescindible parte general que recoja las reglas básicas sobre las que se apoya la actividad sancionadora, a la inversa, se halla extraordinariamente disperso en una barahúnda de leyes sectoriales dictadas en épocas muy distintas y con criterios o perspectivas diversas ${ }^{42}$.

Esta orientación, quedó manifestada en la decisión TC en el año 1996, pronunciándose a propósito de un proyecto de ley que modificaba la Ley de Caza y, recogiendo lo antes indicado, sostuvo que "(...) los principios inspiradores del orden penal contemplados en la Constitución Política de la República han de aplicarse, por regla general, al derecho administrativo sancionador, puesto que ambos son manifestaciones del ius puniendi propio del Estado" ${ }^{43}$.

La doctrina, por su parte, ante este escenario sostuvo que

(...) hoy existe una verdadera transformación del sistema vigente de sanciones administrativas, que más que desconocerlas, intenta adecuar su existencia con los principios del debido proceso, tipicidad y legalidad, lo que implica la necesidad de proyectar el campo de las sanciones administrativas las categorías más depuradas del derecho penal. Esta proyección no viene dada por un mero capricho o una analogía sin fundamento, sino porque esta doctrina nos advierte una clara identidad entre las sanciones administrativas y las puramente penales ${ }^{44}$.

Este criterio lo terminó de confirmar al interior de la Administración Pública, la propia Contraloría el año 2005, quien, citando explícitamente el precedente de la Ley de Caza del TC, para resolver un problema de omisión normativa que regulara la prescripción de una sanción administrativa, señaló que

(...) atendida la inexistencia de una norma especial que regule la prescripción de las infracciones en la materia a que se refiere la presentación de la especie, la consideración del principio básico de la seguridad jurídica y, especialmente, de la garantía constitucional establecida en el artículo $19 \mathrm{~N}^{\circ} 3$ del Texto Supremo, relativa a la igual protección de la ley en el ejercicio de los derechos de las personas, esta Contraloría General debe concluir que para la aplicación de las sanciones que administrativamente disponga la Superintendencia de Electricidad y Combustibles, ese organismo debe tener en consideración las normas pertinentes sobre prescripción establecidas en el Derecho Penal ${ }^{45}$.

\footnotetext{
${ }^{42}$ ARÓSTICA (1991), p. 184.

${ }^{43}$ Tribunal Constitucional, Rol № 244, de 26 de agosto de 1996.

${ }^{44}$ MENDOZA Y ODDO (2003), p. 286.

${ }^{45}$ Dictamen $\mathrm{N}^{\circ} 14.571,22$ de marzo de 2005. Y en el razonamiento previo a esta afirmación, la Contraloría indicó que: “(...) Puntualizado lo anterior, debe anotarse que, tal como lo han sostenido la jurisprudencia de la Contraloría General en su Dictamen N 50.013 bis de 2000, y la doctrina existente sobre la materia, la potestad disciplinaria es una manifestación de la potestad sancionatoria del Estado, la que, a su vez, es junto a la potestad punitiva penal, una de las manifestaciones del ius puniendi general del Estado, razón por la cual ha entendido también que los principios del derecho penal son aplicables al derecho sancionador disciplinario. / El criterio antes reseñado ha sido igualmente recogido por el Tribunal Constitucional, Rol $N^{\circ} 244$, en fallo de 27 de diciembre de 1996, sobre proyecto de ley que modifica la Ley de Caza, el que sostuvo en su considerando $9^{\circ}$ que 'los principios inspiradores del orden penal contemplados en la Constitución Política de la República han de aplicarse, por regla general, al derecho administrativo sancionador, puesto que ambos son manifestaciones del ius puniendi propio del Estado'".
} 


\subsection{La consagración del relato en la jurisprudencia del TC, la Corte Suprema y la Contraloría}

Diez años después del asunto de la Ley de Caza, el mismo TC reiteró lo señalado en 1996, esta vez de la mano del recurso de inaplicabilidad, agregando que

(...) el principio de legalidad es igualmente aplicable a la actividad sancionadora de la administración en virtud de lo prescrito en los dos últimos incisos del numeral 3 del artículo 19 de la Carta Fundamental. Aún cuando las sanciones administrativas y las penas difieren en algunos aspectos, ambas pertenecen a una misma actividad sancionadora del Estado el llamado ius puniendi y están, con matices, sujetas al estatuto constitucional establecido en el numeral 3o del artículo 19. (...) ${ }^{46}$.

A través de la jurisprudencia del TC se comenzó a afirmar la existencia de un ius puniendi estatal matizado en materia administrativa sancionadora. En otras palabras, si bien las infracciones administrativas son sancionadas por el Estado en el ejercicio del derecho punitivo, la reacción de este no podía tener las mismas consecuencias que las que impone el Derecho Penal rodeando su imposición con las mismas garantías de aquel y en tal sentido se explica el vocablo matizado que la judicatura emplea.

Los matices admitidos por la jurisprudencia se han dado a propósito de temas como el principio de tipicidad, forma en que ha de llevarse a cabo el procedimiento, apercibimiento administrativo de arresto, solve et repete, aplicación del principio del non bis in ídem, de la aplicación del principio de proporcionalidad, entre otros.

Por ejemplo, a propósito del principio de tipicidad en relación con la infracción administrativa, el TC ha indicado desde entonces que

(...) esa 'densidad normativa' requerida por el principio de tipicidad viene exigida en razón de la seguridad jurídica de los administrados. La ley, norma cuyo conocimiento debe presumirse, está llamada a establecer las conductas debidas, bajo apercibimiento de sanción administrativa, de un modo suficiente para que los obligados tomen noticia al menos del núcleo esencial de la conducta que les resulta obligatoria, bajo apercibimiento de sanción ${ }^{47}$,

y que "(...) la administración no está constitucionalmente facultada para sancionar, si las conductas que se suponen infringidas están descritas únicamente en normas reglamentarias que no tengan suficiente cobertura legal" 48 .

En relación con la forma en que la autoridad administrativa ha de llevar a cabo un procedimiento sancionatorio cuando no se contempla formalmente un procedimiento especial para tal efecto, el TC ha indicado que

(...) tal omisión se salvaría si al ejercer dichas competencias la autoridad instruye una investigación que cumpla las exigencias básicas que caracterizan un debido proceso, como la formulación de cargos, su notificación al inculpado, seguida de una oportunidad efectiva para que éste pueda ejercer

\footnotetext{
${ }^{46}$ Tribunal Constitucional, Rol № 480, de 27 de julio de 2006, considerando $5^{\circ}$. En el mismo sentido, Tribunal Constitucional, rol № 479, de 8 de agosto de 2006. La misma sentencia, recalcó además que: “(...) la aplicación de las garantías constitucionales del Derecho Penal al Derecho Administrativo sancionador tiene una larga tradición en el derecho chileno, pues ya hace cuarenta años, la Corte Suprema interpretó que la voz "condenados" del artículo 11 de la Constitución de 1925 era aplicable a quienes sufrían sanciones administrativas (...). De ese modo, hace ya cuarenta años nuestra Corte Suprema hacía aplicables al derecho administrativo sancionador las garantías constitucionales propias del derecho penal".

${ }^{47}$ Tribunal Constitucional, Rol № 480, de 27 de julio de 2006, considerando 22.

${ }^{48}$ Tribunal Constitucional, Rol № 479, de 8 de agosto de 2006, considerando 19 .
} 
el derecho a defensa, incluida la posibilidad de allegar y producir pruebas, así como la posibilidad de impugnar lo resuelto en sede jurisdiccional ${ }^{49}$.

En cuanto a la aplicación de apremios por parte de una autoridad administrativa, ordenando por ejemplo, el ingreso a un recinto penal de un sujeto que no haya pagado una multa impuesta en un sumario sanitario ${ }^{50}$, el referido tribunal consideró que esto resultaba inconstitucional pues se trata de un verdadero apremio ilegítimo, al implicar una pena privativa de libertad impuesta por la vía administrativa sin que previamente exista una instancia jurisdiccional que revise dicha actuación, por lo que ello vulnera el artículo 19, números $1^{\circ}$ y $7^{\circ}$, de la Constitución ${ }^{51}$.

En relación con la constitucionalidad de exigir el pago total o parcial de una obligación impuesta por la autoridad administrativa para acceder a la jurisdicción - solve et repete-, la jurisprudencia constitucional sostuvo que con ella "(...) se infringe el derecho de acceso a la justicia y a la tutela judicial efectiva porque se establece la exigencia legal que supedita la posibilidad de reclamar ante el juez la validez de una multa administrativa, al pago previo del todo o parte" ${ }^{52}$. Se trata de un privilegio procesal que "(...) implica un condicionamiento de la admisibilidad de los reclamos administrativos o las acciones contencioso-administrativas" 53 y por eso el TC ha cuestionado su legitimidad ${ }^{54} 55$.

EI TC también ha establecido que no puede existir potestad sancionatoria sin revisión judicial plena, al sentenciar que

(...) si bien puede resultar lícito que los órganos fiscalizadores puedan, previo al proceso judicial y en el ámbito administrativo, determinar la existencia de una infracción y la cuantía de una multa, la sanción no puede estimarse como cierta e irrevocable para el ordenamiento jurídico sino una vez que haya sido resuelto en sede jurisdiccional e independiente. Así lo consagra nuestro sistema al permitir que se recurra de las respectivas decisiones administrativas ante los tribunales, cuestión que no sólo está consagrada a nivel legal, sino que también, con mayor jerarquía, en la propia Constitución Política (artículo 38, inciso segundo) ${ }^{56}$.

Finalmente, el TC en una de las últimas oleadas de criterios clásicos para el Derecho Administrativo Sancionador bajo la lectura del ius puniendi, concentró su atención en los elementos para determinar el quantum de la sanción, señalando que la indeterminación de una regla al definir la sanción compromete el principio de proporcionalidad y el debido proceso. Los asuntos vinculados al denominado caso "Cascadas" fueron el contexto donde construyó esa argumentación ${ }^{57}$.

\footnotetext{
${ }^{49}$ Tribunal Constitucional, Rol № 2.784, de 12 de mayo de 2016, considerando 12. En el mismo sentido Tribunal Constitucional, Rol № 2682, de 30 de octubre de 2014.

${ }^{50}$ Aplicación del artículo 169 del Código Sanitario.

${ }^{51}$ Tribunal Constitucional, Rol № 1.518, de 21 de octubre de 2010.

52 Tribunal Constitucional, Rol № 2.853, de 24 de diciembre de 2015. En el mismo sentido Tribunal Constitucional, Rol № 2.036, de 18 de octubre de 2011, considerando 22 y Tribunal Constitucional, Rol № 2.452, de 17 de octubre de 2013.

${ }^{53}$ Tribunal Constitucional, Rol № 946, de 1 de julio de 2008, considerando 30.

54 “(...) esta misma Magistratura, en el pasado, no ha objetado la legitimidad del accionar judicial de los órganos de la Administración, sino que la existencia de ciertos privilegios procesales. Así sucedió con el solve et repete (STC $N^{\circ}$ Rol $N^{\circ} 1345 / 2009$ ) y la ejecutoriedad de la sanción administrativa (STC Rol N 1518/2010)”. Tribunal Constitucional, rol № 2.997, de 13 de junio de 2017. En el mismo sentido Tribunal Constitucional, rol № 2.895, de 6 de diciembre de 2016.

${ }^{55}$ Es posible encontrar fallos en los cuales el Tribunal Constitucional ha indicado que el solve et repete es constitucional mientras no se trate "de una exigencia dineraria que grave el caudal del apelante". Tribunal Constitucional, Rol № 2.934, de 1 de diciembre de 2016, considerando 35.

${ }^{56}$ Tribunal Constitucional, Rol № 792, de 3 de enero de 2008, considerando 16.
} 
Por su parte, la Corte Suprema, se ha pronunciado utilizando el mismo relato del TC al afirmar la existencia de un único ius puniendi del Estado y la aplicación matizada de las garantías del Derecho Penal al Derecho Administrativo Sancionador, a propósito de diversos sectores de referencia tales como laborales, eléctricas, medio ambientales, educación y sanitarias, siendo explícita al señalar que

(...) esta Corte ha declarado en otras oportunidades que existe cierto consenso jurídico en cuanto a que la sanción penal y la sanción administrativa constituyen manifestaciones del ejercicio de un único poder estatal sancionatorio, el denominado ius puniendi estatal. Sin embargo, nuestro país carece de una normativa general sobre el ámbito sancionatorio administrativo y responde la legislación, más bien, a un carácter sectorial ${ }^{58}$.

Agregando - en términos similares a lo indicado por el TC- que

(...) la potestad sancionadora de la Administración admite un origen común con el Derecho Penal en el ius puniendi del Estado, por lo que le resultan aplicables los mismos principios, límites y garantías que en la Carta Fundamental se prescriben para el derecho punitivo, aunque ese traspaso haya de producirse con ciertos matices en consideración a la particular naturaleza de las contravenciones administrativas ${ }^{59}$.

Por ejemplo y a propósito de la relación entre el principio de reserva legal y la aplicación del Derecho Administrativo Sancionador, la Corte Suprema ha señalado que

(...) el principio de la reserva legal no tiene en el campo del Derecho Administrativo Sancionador una aplicación tan rigurosa como en el Derecho Penal (...) el principio de reserva, en su variable de tipicidad, se satisface dentro del área del Derecho Sancionatorio Administrativo con la sola exigencia de describirse en la ley el núcleo esencial de las conductas afectas a sanción, complementándose las restantes especificaciones y graduaciones típicas mediante cuerpos normativos de índole reglamentaria ${ }^{60}$.

Quizá uno de los aspectos más relevantes de la jurisprudencia de la Corte Suprema en materia de Derecho Administrativo Sancionador, fue el establecimiento del denominado "decaimiento del procedimiento sancionador", que sobre la base de la configuración de plazos del procedimiento administrativo señaló que transcurrido un plazo - que en su jurisprudencia fue variando- sin que la Administración ejerciera su potestad habiendo iniciado el procedimiento administrativo, este perdía objeto y decaía dando origen a una abundante jurisprudencia debatida por la doctrina nacional ${ }^{61}$, criterio que finalmente quedó incorporado en los procedimientos administrativos especiales regulados en las leyes de aseguramiento de la calidad y educación superior.

\footnotetext{
${ }^{57}$ El caso inicial fue: Tribunal Constitucional, Rol № 2.922, 30 de octubre de 2015. Esta tesis se reprodujo con posterioridad en los asuntos: Tribunal Constitucional, Rol № 3.014, de 4 de abril de 2016; Rol № 3.236, de 6 de octubre de 2016; Rol № 3.542, 2 de junio de 2017; Rol № $3.575,13$ de junio de 2017; Rol № 3.932 y Rol № 42.230, ambos de 24 de enero de 2019.

${ }^{58}$ Corte Suprema, Rol № 17.736-2016, de 13 de diciembre de 2016, considerando $9^{\circ}$. En el mismo sentido Corte Suprema, Rol № 41.8152016, de 1 de marzo 2017.

${ }^{59}$ Corte Suprema, Rol № 7.112-2017, de 8 de junio de 2017, considerando $6^{\circ}$. En el mismo sentido Corte Suprema, Rol № 14.432-2013, de 18 de agosto de 2014.

${ }^{60}$ Corte Suprema, Rol № 4.404-2005, de 8 de noviembre de 2005, considerando 26.

${ }^{61}$ CORDERO (2011), p. 243; VALDIVIA Y BLACKE (2015), p. 94.
} 
Por último, Contraloría a través de su jurisprudencia administrativa, ha reconocido sistemáticamente y prácticamente sin variaciones la existencia de un único ius puniendi estatal, señalando al efecto que:

(...) la jurisprudencia contenida, entre otros, en los dictámenes $\mathrm{N}^{\circ}$ s. 14.571 y 31.239 , ambos de 2005; 63.697, de 2011, y 13.790, de 2013, de esta Contraloría General, ha expresado que tanto la potestad sancionadora penal como administrativa, constituyen una manifestación del ius puniendi general del Estado, motivo por el cual se ha entendido que los principios del derecho penal, entre ellos, el de culpabilidad, son aplicables, con matices, al derecho administrativo sancionador ${ }^{62}$.

\subsection{La materialización legislativa del Derecho Administrativo Sancionador en los sectores de referencia}

Como se ha podido apreciar el relato sobre el Derecho Administrativo Sancionador en la jurisprudencia judicial, constitucional y administrativa sobre la base del denominado ius puniendi estatal se transformó en un estándar, en algún sentido acrítico sobre sus implicancias, desde 2005 en adelante. Sin embargo, esa jurisprudencia delimitó los contornos sobre los cuales se ha debatido académicamente en el Derecho Administrativo nacional ${ }^{63}$. Pero el legislador, mientras esa intensidad se manifestaba, también desarrolló una construcción normativa que trató, desde los sectores de referencia relevantes del último tiempo, de establecer estándares que de algún modo se han ido homologando progresivamente.

Hasta el año 2003 solo existían leyes especiales que consagraban la potestad sancionatoria de la Administración, sin un procedimiento determinado para su aplicación. No obstante, en mayo del año 2003, con la dictación de la ley № 19.880 sobre Bases de los Procedimientos Administrativos ("LBPA"), se reguló un procedimiento administrativo con carácter de supletorio ${ }^{64}$. Dicha normativa consagró, entre otras cosas, principios, derechos, obligaciones y recursos aplicables para efectos de llevar a cabo cualquier tipo de procedimiento administrativo. Frente a la inexistencia de un procedimiento administrativo sancionatorio, la jurisprudencia ha reconocido que la LBPA constituye el procedimiento supletorio por excelencia. Así, ha sentenciado que dicho cuerpo legal se aplica en todas aquellas materias no previstas por la legislación especial y en la medida que sea conciliable con el objetivo o misión del ente administrativo que lleva a cabo el procedimiento sancionatorio ${ }^{65}$, en atención a su carácter de ley de bases, que establece las

(...) reglas y principios básicos que se deben aplicar de forma imperativa, sirviendo no sólo para llenar vacíos legales en materias carentes de regulación expresa sino que además deben orientar cualquier interpretación de normas ambiguas relacionadas con la materia regulada por ellas ${ }^{66}$.

En agosto del año 2003 se publicó la ley № 19.884, sobre "Transparencia, límite y control del gasto electoral", la que comprende disposiciones aplicables a los órganos de la Administración del Estado y establece procedimientos administrativos sancionatorios para infracciones cometidas tanto por particulares o entidades aportantes, como por candidatos o partidos políticos en relación

\footnotetext{
62 Dictamen $N^{\circ} 60.341$, de 23 de septiembre de 2013.

${ }^{63}$ Ver nota 1.

${ }^{64}$ Artículo 2을 Ley № 19.880, de 2003.

${ }^{65}$ Corte Suprema, Rol № 62.128-2016, de 9 de mayo de 2017, considerando 11.

${ }^{66}$ Corte Suprema, Rol № 62.128-2016, de 9 de mayo de 2017, considerando 13.
} 
con el financiamiento privado, transparencia del financiamiento y aportes a campañas electorales ${ }^{67}$. Sobre la base de esta ley, el TC sentenció que no resultaba posible la imposición de una sanción sin la incoación previa de un procedimiento, declarando en consecuencia la inconstitucionalidad de las normas sancionatorias contempladas en la ley, al impedir la adecuada defensa por parte de los afectados $^{68}$.

Como consecuencia de lo anterior, el Ejecutivo presentó un proyecto de ley que buscaba establecer las bases de los procedimientos administrativos sancionatorios ${ }^{69}$; no obstante, la iniciativa fue archivada, por lo que finalmente debió dictarse una nueva norma que se encargara de regular los procedimientos administrativos a los que debe sujetarse la aplicación de sanciones por infracciones a la ley de gasto electoral ${ }^{70}$.

En noviembre de ese mismo año, se publicó la ley N¹9.911 que “Crea el Tribunal de Defensa de la Libre Competencia", la cual modificó el Decreto Ley N211, de 1973 y estableció un tribunal contencioso administrativo, que tiene como función, entre otras, prevenir, corregir y sancionar los atentados a la libre competencia" ${ }^{71}$, aunque sometida a un sistema de "contencioso represivo" 72 . En diciembre del año 2003 se dictó la ley №19.913 que "Crea la Unidad de Análisis Financiero y modifica diversas disposiciones en materia de lavado y blanqueo de activos", unidad que tiene por objeto prevenir e impedir la utilización del sistema financiero y de otros sectores de la actividad económica, para la comisión de determinados delitos descritos en la propia normativa ${ }^{73}$, confiriéndole a dicho órgano facultades para aplicar sanciones administrativas ${ }^{74}$. Dicha ley fue modificada en el año 2006 mediante la ley $\mathrm{N}^{\circ} 20.119$, agregando un título sobre infracciones y sanciones en el que se regulan distintos tipos de infracciones asociados a una escala de sanciones según su gravedad ${ }^{75}$, así como las reglas a las que debe someterse el procedimiento para la aplicación de sanciones: formulación de cargos y su notificación; plazo para evacuar los descargos; término probatorio y sistema de valoración de la prueba; contenido de la resolución que ponga

\footnotetext{
${ }_{67}$ Párrafo 5, artículos 27 A y siguientes de la Ley № 19.884, de 2003. Cabe hacer presente que la referida ley fue objeto de una modificación mediante la Ley № 20.053, de 2005.

${ }^{68}$ En efecto, el Tribunal Constitucional en el control de constitucionalidad del referido proyecto declaro la inconstitucionalid ad del inciso tercero del artículo $3^{\circ}$, artículo $6^{\circ}$, inciso sexto del artículo 22, artículo 29, artículo 30 , inciso final del artículo 34 e inciso final del artículo 47) pues: “(...) del examen de las disposiciones transcritas en el considerando anterior, se desprende que, en ninguna de ellas, se contempla un procedimiento que permita al afectado una adecuada defensa de sus derechos, en sede administrativa, en forma previa a la imposición de las sanciones que en cada caso se establecen; // Que, resulta evidente en consecuencia, que el Legislador ha dejado de cumplir con la obligación que el Poder Constituyente le impone, de dictar las normas tendientes a asegurar la protección y defensa jurídica de los derechos fundamentales de quienes se encuentren comprendidos en las situaciones que, de acuerdo con las disposiciones indicadas, determinan la implosión de una sanción. A mayor abundamiento, lo recién advertido por este Tribunal puede lesionar el ejercicio de los derechos comprometidos, circunstancia que pugna con las garantías que, en los incisos primero y segundo del numeral tercero, del artículo 19, la Carta Fundamental consagra para resguardarlos". Tribunal Constitucional, Rol № 376, de 17 de junio de 2003 , considerandos 34 y 35 .

${ }^{69}$ Boletín N⒊475-06, "Proyecto de ley que establece las bases de los procedimientos administrativos sancionatorios y modifica la ley № 19.884, sobre transparencia, límite y control del gasto electoral". Archivado en agosto de 2006.

${ }^{70}$ Ley $\mathrm{N}^{\circ} 19.963$, de 2004.

${ }^{71}$ Artículo 70, Ley № 19.911, de 2003.

72 El contencioso represivo tiene por objeto que el juez aplique medidas de gravámenes concretas a un particular, como puede ser en los casos que la sanción debe ser aplicada por el juez y no por la Administración. La Administración carece de potestad sancionadora directa, por lo cual se requiere recurrir a un tribunal para la aplicación de la misma. CORDERO (2015), p. 620.

${ }^{73}$ Artículo 10, Ley № 19.913, de 2003.

${ }^{74}$ Artículo $2^{\circ}$, letra j, Ley №19.913, de 2003.

${ }^{75}$ Los artículos 19 y 20 de la Ley $\mathrm{N}^{\circ} 19.913$, de 2003, establecen distintas sanciones para las infracciones que se califiquen como leves, menos graves y graves.
} 
término al procedimiento ${ }^{76}$ y recursos en contra de las resoluciones dictadas a lo largo del procedimiento $^{77}$.

En el mes de enero del año 2005 se dictó la ley №19.995 que "Establece las bases generales para la autorización, funcionamiento y fiscalización de casinos de juego", la cual creó la Superintendencia de Casinos y otorgó al Superintendente la facultad de imponer las sanciones y multas establecidas respecto de las infracciones que la propia ley especifica ${ }^{78}$, regulando para tales efectos un procedimiento sancionatorio ${ }^{79}$. Como reglas de dicho procedimiento estableció los requisitos de admisibilidad de las denuncias; la necesidad de efectuar una formulación de cargos en caso que se estime que hay mérito suficiente en la denuncia o investigación efectuada de oficio por la autoridad; la forma de notificación de la misma y de las demás resoluciones al supuesto infractor; el plazo para evacuar los descargos; el término probatorio; medios de prueba aceptados y sistema de valoración de la prueba aplicable; los requisitos que debe satisfacer la resolución que ponga término al procedimiento y los recursos que procedan en contra de la misma.

En marzo de 2005 se publicó la ley № 20.004 que “Modifica ley № 18.175, en materia de fortalecimiento de la transparencia en la administracion privada de las quiebras, fortalecimiento de la labor de los sindicos y de la superintendencia de quiebras", mediante la cual se otorgó potestades sancionatorias de las que hasta ese momento carecía la entonces Fiscalía Nacional de Quiebras respecto los síndicos y los administradores de la continuación del giro, en caso de incumplimiento de las instrucciones que dicha institución impartiese y de las normas que fijase, y que como correlato de lo anterior sujetó el ejercicio de dicha potestad a reglas procedimentales mínimas, entre las cuales se encuentran la exigencia de audiencia previa y posibilidad de revisión judicial ${ }^{80}$.

En enero de 2009 se publicó ley $N^{\circ} 20.322$, que "Fortalece y perfecciona la jurisdicción tributaria y aduanera" creando para tales efectos, nuevos tribunales contencioso administrativo; los Tribunales Tributarios y Aduaneros ("TTA"), con competencia contenciosa administrativa de revisión de las decisiones del Servicio de Impuestos Internos ("SII") y del Servicio Nacional de Aduanas en ejercicio de su potestad sancionatoria -entre otras funciones-. Para lo anterior, la ley $N^{\circ} 20.322$ modificó el Código Tributario en lo relativo a actuaciones de fiscalización, procedimientos de giro, liquidación y otros que incidan en el pago o determinación de un impuesto, y procedimientos de reclamación ante los TTA en contra de dichas decisiones del SII ${ }^{81}$; así como la Ordenanza General de Aduanas en lo relativo - entre otras materias - al procedimiento de reclamación ante el TTA en contra la sanción de cancelación y de las liquidaciones, cargos y actuaciones que sirvan de base para la fijación del monto o determinación de diferencias de derechos, impuestos, tasas o gravámenes impuestas por el Director Nacional de Aduanas ${ }^{82}$.

También en el año 2009 se publicó la ley № 20.378, que "Crea un subsidio nacional para el transporte público remunerado de pasajeros", y regula sanciones a imponer por parte del Secretario Regional Ministerial de Transportes y Telecomunicaciones respectivo o del Subsecretario de

\footnotetext{
${ }^{76}$ Artículo 11, Ley N¹9.913, de 2003.

${ }^{77}$ Artículos 23 y 24, Ley N¹9.913, de 2003.

${ }^{78}$ Artículo 42 número 11, Ley №19.995, de 2005.

${ }^{79}$ Artículo 55, Ley № 19.995, de 2005.

${ }^{80}$ Artículo № 1 letra d) del artículo único de la Ley № 20.004, de 2005.

${ }^{81}$ De esta manera, se buscó perfeccionar el régimen de revisión judicial tributaria que en primera instancia se encontraba dentro del propio SII, lo que provocaba reparos respecto a la independencia de los jueces tributarios. Por lo anterior, la Ley $\mathrm{N}^{\circ} 20.322$, de 2009 , separó la función sancionatoria de la jurisdiccional.

${ }^{82}$ Con esto se buscaba el mismo objetivo que con la modificación en materia tributaria, toda vez que con anterioridad a la Ley $\mathrm{N}^{\circ} 20.322$, de 2009, los reclamos eran conocidos por la Junta General de Aduanas y no por un tribunal ajeno a la autoridad administrativa. Esta ley fue modificada por la Ley № 21.039, de 2017, en relación a las competencias de revisión de la autoridad tributaria y aduanera.
} 
Transportes respecto de las personas que perciban indebidamente los recursos provenientes del subsidio creado por dicha ley. Para ello, sujetó la imposición de sanciones al procedimiento creado al efecto, el cual contempló reglas básicas relativas a formulación de cargos, plazo para efectuar descargos, término probatorio, reglas de apreciación de la prueba y recursos en contra de la resolución sancionatoria; y en un aspecto que resulta relevante en la evolución normativa del Derecho Administrativo Sancionador, estableció criterios para la determinación de las sanciones establecidas ${ }^{83}$.

En enero de 2010 se publicó la ley № 20.417, que "Crea el Ministerio, el Servicio de Evaluación Ambiental y la Superintendencia del Medio Ambiente". Ella reformó varias materias en temas ambientales, otorgándole a la Superintendencia la facultad de fiscalizar las Resoluciones de Calificación Ambiental, las medidas de los Planes de Prevención y/o de Descontaminación Ambiental, el contenido de las Normas de Calidad Ambiental y Normas de Emisión, los Planes de Manejo, cuando corresponda, y todos aquellos otros instrumentos de carácter ambiental que establezca la ley ${ }^{84}$, e imponer sanciones de conformidad con lo señalado en la referida norma, creando para tales efectos un procedimiento sancionatorio ${ }^{85}$.

Dicho procedimiento sancionatorio recogió la evolución normativa respecto de las etapas y requisitos propios de un procedimiento de estas características ${ }^{86}$, pero además estableció un nuevo estándar en materia de procedimiento para la imposición de sanciones, al regular, entre otros aspectos, la separación entre las funciones de instrucción y sanción, la legitimación de los denunciantes para intervenir durante el procedimiento administrativo sancionador, la posibilidad de auto denuncia, una regla específica de medidas provisionales más allá de lo contemplado en la LBPA y las autorizaciones judiciales requeridas para la adopción de algunas de ellas que resulten especialmente gravosas, así como la posibilidad de efectuar salidas alternativas al procedimiento sancionatorio. Adicionalmente, la ley №20.417 consagró una regla expresa para evitar infracciones al principio de non bis in ídem, al disponer que "[e]n ningún caso se podrá aplicar al infractor, por los mismos hechos y fundamentos jurídicos, dos o más sanciones administrativas" ${ }^{87}$.

En febrero del mismo año, se publicó la ley № 20.416, que "Fija normas especiales para las empresas de menor tamaño", con el objeto de facilitar el desenvolvimiento de las empresas de menor tamaño, mediante la adecuación y creación de normas vinculadas a la operación de este tipo de empresas ${ }^{88}$. Esto significó un avance al establecer reglas sobre transparencia de los procedimientos de fiscalización, al considerar la posibilidad de declaración voluntaria de incumplimiento en el ámbito sanitario, y una distinción entre las sanciones a imponer por infracciones a la legislación laboral según el tamaño de la empresa.

En agosto de 2011 se publicó la ley º20.529, sobre el "Sistema nacional de aseguramiento de la calidad de la educación parvularia, básica y media y su fiscalización", creándose con ella la Superintendencia de Educación, a la que, en el ejercicio de sus potestades de fiscalización,

\footnotetext{
${ }^{83}$ En efecto, el artículo 9o de la Ley № 20.378, de 2009, dispuso que para la determinación de las sanciones establecidas, se considerarán las siguientes circunstancias: "a) El beneficio económico obtenido con motivo de la infracción. / b) La intencionalidad en la comisión de la infracción y el grado de participación en el hecho, acción u omisión constitutiva de la misma. / c) La conducta anterior del infractor".

${ }^{84}$ Artículo 20, Ley № 20.417, de 2010.

${ }^{85}$ Artículo 38 y siguientes, Ley № 20.417, de 2010.

${ }^{86}$ En efecto, la Ley $\mathrm{N}^{\circ} 20.417$, de 2010, recogió la evolución legislativa en la materia al establecer una regulación específica del procedimiento sancionador a cargo de la Superintendencia, efectuar una especificación y clasificación de las sanciones, incor porar una regulación de la prueba y del contenido de la resolución sancionatoria, considerar recursos administrativos especiales además de los contemplados en la LBPA, así como un sistema especial de revisión judicial.

${ }^{87}$ Inciso segundo del artículo 60 del doble articulado del artículo $2^{\circ}$ de la Ley №20.417, de 2010.

${ }^{88}$ Artículo 1으, Ley № 20.416, de 2010.
} 
le corresponde formular cargos, instruir los procedimientos administrativos sancionatorios e imponer las sanciones correspondientes por infracción a la normativa educacional, así como aquellas que proponga la Agencia Nacional de Educación, de conformidad con el procedimiento administrativo sancionador especial regulado al efecto, que siguió el modelo de procedimiento sancionatorio de la ley $\mathrm{N}^{\circ} 20.417$ a cargo de la Superintendencia del Medio Ambiente, consolidándolo ${ }^{91}$, , pero incorporando adicionalmente y por primera vez una regla sobre caducidad del procedimiento administrativo sancionador ${ }^{93}$, hasta ese momento reconocido solo por la jurisprudencia mediante la jurisprudencia del decaimiento del procedimiento administrativo sancionador.

En junio de 2012 se crearon nuevamente tribunales contenciosos administrativos especiales con la publicación de la ley №20.600 que "Crea los Tribunales Ambientales", estableciendo un contencioso de revisión pleno en materia de las sanciones administrativas impuestas por la Superintendencia del Medio Ambiente.

En febrero de 2017 se publicó la ley №21.000, que "Crea la Comisión para el Mercado Financiero" con el objeto de, entre otros, velar por el correcto funcionamiento, desarrollo y estabilidad del mercado financiero ${ }^{94}$. Esta Comisión cuenta con una unidad de investigación responsable de la instrucción del procedimiento sancionatorio cuya regulación se precisa en la normativa ${ }^{95}$, confiriéndole además las potestades para resolver dichos procedimientos y aplicar las sanciones que correspondan, según sea el caso $^{96}$. De esta manera, además de incorporar los aspectos procedimentales ya asentados en la legislación sectorial ${ }^{97}$, se avanzó un paso adicional en términos de regulación del procedimiento administrativo, ordenándose, además, la facultad de la autoridad de aplicar medidas correctivas y medidas intrusivas y la posibilidad del infractor de efectuar una delación compensada, así como incorporar los criterios de proporcionalidad de las sanciones que el TC había objetado tras los casos "Cascadas".

Sin embargo, en esta progresiva materialización legislativa, en enero de 2018 el TC decidió declarar inconstitucional las normas del proyecto de ley que modernizaba al Servicio Nacional del Consumidor que había aprobado el Congreso ${ }^{98}$ y que le entregaban un conjunto de competencias nuevas, incluidas las sancionatorias. Pero dicha decisión debe apreciarse con cuidado para efectos del argumento de este trabajo. Para el TC lo que resultaba inconstitucional no eran la potestad sancionatoria en poder de la Administración, sino que un conjunto de facultades conservativas, cautelares o de mediación adicionales, que solo pueden ser adoptadas por organismos jurisdiccionales en opinión del tribunal y, en consecuencia, no podían quedar incorporadas dentro

\footnotetext{
${ }^{91}$ Artículos 47 y siguientes, Ley N²0.529, de 2011.

92 En efecto, la Ley $N^{\circ} 20.529$, de 2011, contempla reglas en materia de especificación y clasificación de las sanciones, otorga elementos para la determinación de las sanciones, separa las funciones de instrucción de las de sanción, otorga la posibilidad de adoptar medidas provisionales, contempla la regulación de la prueba y del contenido de la resolución sancionatoria, y la existencia de recursos administrativos especiales en contra de las resoluciones sancionatorias de la autoridad.

${ }^{93}$ Artículo 86, Ley № 20.529, de 2011.

${ }^{94}$ Artículo $1^{\circ}$, Ley № 21.000, de 2017.

${ }^{95}$ Artículo 22, Ley № 21.000, de 2017.

${ }^{96}$ Artículo 40 y siguientes, Ley № 21.000, de 2017.

97 Así, la Ley N 21.000, de 2017, también contempla reglas en materia de especificación y clasificación de las sanciones, otorga elementos para la determinación de las sanciones, separa las funciones de instrucción de las de sanción, concede la posibilidad de adoptar medidas provisionales y precisa la necesidad de contar con autorización judicial previa para ciertos casos, establece la posibilidad de auto denuncia y de alcanzar salidas negociadas alternativas a la imposición de una sanción administrativa, determina la regulación de la prueba y del contenido de la resolución sancionatoria, y contempla la existencia de recursos administrativos especiales en contra de las resoluciones sancionatorias de la autoridad.

98 Tribunal Constitucional, Rol 4012-2017, de 18 de enero de 2018, considerandos 23 y 33.
} 
de las atribuciones sancionatorias de un organismo administrativo, porque la el todo era más que las partes individualmente consideradas.

Esto explica que con posterioridad el TC admitiera sin inconvenientes las facultades de la Superintendencia de Educación Superior ${ }^{99}$, que con la dictación de la ley № 21.091 en mayo de 2018, "Sobre Educación Superior", reguló la potestad sancionatoria de dicha entidad ${ }^{100}$ siguiendo el modelo establecido tras la dictación de la ley № 20.529 sobre aseguramiento de la calidad en materia escolar que, como se explicó, siguió el modelo aprobado por el Congreso tras la reforma a la institucionalidad ambiental por medio de la ley № 20.417.

Como se puede apreciar, así como la jurisprudencia constitucional, judicial y administrativa elaboraron criterios sustantivos y materiales para la aplicación del Derecho Administrativo Sancionador, el legislador fue también, progresivamente regulando dicha potestad, reconociendo la aplicación de un conjunto de criterios que toda potestad sancionatoria en manos de la Administración debe cumplir, pero probablemente sobre la base de un relato distinto. A diferencia de la jurisprudencia, el legislador desde hace un poco más de una década ha visto en la potestad sancionatoria de la Administración uno de los elementos adicionales para garantizar el cumplimiento de las regulaciones que tratan de promover el bien público. La idea es relativamente simple: "los entes administrativos usualmente estarán mejor capacitados para asegurar el cumplimiento persuasivo de las normas cuando cuenten con facultades para aplicar sanciones administrativas" ${ }^{101}$, por eso la construcción normativa de la ley persigue dicho propósito antes que el énfasis en la simple restricción de la potestad para garantizar un derecho individual. Como señaló Nieto "la potestad administrativa sancionadora forma parte ínsita de la competencia de gestión"102.

\section{La importancia de los sectores de referencia en la reconfiguración del Derecho Administrativo Sancionador chileno}

La doctrina del Derecho Administrativo que se ha dedicado a pensar sobre los sectores de referencia, específicamente en el Derecho comparado, ha señalado que los clásicos ámbitos que estos representaban se encontraban vinculados con materias sanitarias, urbanísticas, poderes de policía, régimen local o municipal y la función o empleo público ${ }^{103}$. Pero en los tiempos presentes otros sectores han actuado como "laboratorios de regulación"104 como sucede con: medio ambiente, mercados financieros, educación, libre competencia, migraciones, entre otros. A partir de ellos, se ha ido configurando una relación dialéctica entre la parte general y especial del Derecho Administrativo, en un mundo donde cada vez es más difícil predicar de las reglas legales generales poderes para la Administración, dando origen a lo que Vermule denomina "la abdicación del Derecho" a favor de la Administración ${ }^{105}$.

Pero tal como se anticipaba el retraso de una parte general normativamente concebida desde el 2003, con sectores que operaron de modo autónomo sin un criterio unificador es especialmente evidente en materia de Derecho Administrativo Sancionador, donde a través de la

\footnotetext{
99 Tribunal Constitucional, Rol 4317-2018, de 26 de abril de 2018.

100 Artículo 45 y siguientes, Ley № 21.091, de 2018.

${ }^{101}$ MONTT (2011), p. 74. La idea de Montt esta construida sobre el clásico texto de AYRES Y BRAITHWAITE (1992) que marcó esta manera de comprender los poderes sancionatorios de la Administración para garantizar el cumplimiento.

102 NIETO (2005), p. 96.

103 SCHMIDT-ASSMAN (2003), p. 13; PAREJO (2012), p. 598.

104 SCHMIDT-ASSMAN (2012), p. 184.

105 VERMULE (2016), pp. 3-16.
} 
demanda de un régimen de garantías común nacido de una interpretación de la Constitución se desarrolló una jurisprudencia constitucional, administrativa y judicial sobre la base de la idea de ius puniendi.

¿Dónde está entonces el aporte de los sectores de referencia? En mi opinión en las regulaciones normativas iniciadas a partir de 2003, que fueron potenciadas tras la consolidación jurisprudencial de 2006 en adelante y que han ido entregando aportes progresivos y marginales para una explicación conceptualmente mayor. Un simple listado a título referencial, comparando criterios o elementos sancionatorios de sectores de referencias clásicos, como el que emana del Código Sanitario, con los contemporáneos, entendiendo por estos los regulados en los últimos años en nuestro país, permiten aproximarnos a esa conclusión ${ }^{106}$.

\begin{tabular}{|c|c|c|c|c|c|}
\hline & \begin{tabular}{|l} 
Sanitario \\
$(1967)$
\end{tabular} & $\begin{array}{l}\text { Tributario } \\
\text { (2009) }\end{array}$ & $\begin{array}{l}\text { Medio } \\
\text { Ambiente } \\
(2010) \\
\end{array}$ & $\begin{array}{l}\text { Educación } \\
\text { Escolar } \\
(2011)\end{array}$ & $\begin{array}{l}\text { Mercados } \\
\text { Financieros } \\
(2017) \\
\end{array}$ \\
\hline $\begin{array}{l}\text { 1.Especificación } \\
\text { de sanciones }\end{array}$ & $\mathrm{V}$ & $\mathrm{V}$ & $\mathrm{V}$ & $\mathrm{V}$ & $\mathrm{V}$ \\
\hline $\begin{array}{l}\text { 2.Clasificación de } \\
\text { sanciones }\end{array}$ & $\mathrm{V}$ & $\mathrm{V}$ & $\mathrm{V}$ & $\mathrm{V}$ & $\mathrm{V}$ \\
\hline $\begin{array}{l}\text { 3.Elementos } \\
\text { para su } \\
\text { determinación }\end{array}$ & - & $\mathrm{V}$ & $v$ & $v$ & $\mathrm{~V}$ \\
\hline $\begin{array}{l}\text { 4.Medidas } \\
\text { correctivas sin } \\
\text { procedimiento } \\
\text { sancionador }\end{array}$ & 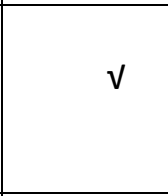 & 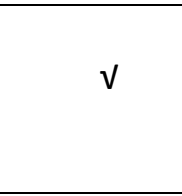 & - & - & $v$ \\
\hline $\begin{array}{l}\text { 5. Regulación } \\
\text { específica del } \\
\text { procedimiento } \\
\text { sancionador }\end{array}$ & 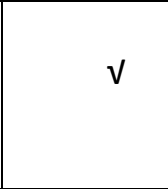 & $V$ & $\mathrm{~V}$ & $\mathrm{~V}$ & $v$ \\
\hline $\begin{array}{l}\text { 6.Separación } \\
\text { entre instrucción } \\
\text { y sancionador }\end{array}$ & $x$ & $x$ & $\mathrm{~V}$ & $\mathrm{~V}$ & $\mathrm{~V}$ \\
\hline $\begin{array}{l}\text { 7.Legitimación } \\
\text { de denunciantes }\end{array}$ & - & - & $\mathrm{V}$ & - & - \\
\hline $\begin{array}{l}\text { 8.Medidas } \\
\text { provisionales }\end{array}$ & - & - & $\mathrm{V}$ & $\mathrm{V}$ & $\mathrm{V}$ \\
\hline $\begin{array}{l}\text { 9.Medidas } \\
\text { intrusivas }\end{array}$ & $x$ & $x$ & $x$ & $x$ & $\mathrm{~V}$ \\
\hline $\begin{array}{l}10 . \\
\text { Autorizaciones } \\
\text { Judiciales } \\
\text { intermedias }\end{array}$ & $x$ & $x$ & $\mathrm{~V}$ & $x$ & $\mathrm{~V}$ \\
\hline
\end{tabular}

106 Para efectos de la comparación, hemos tomado como referencia ámbitos representativos en donde la administración ejerce directamente la potestad sancionatoria. 


\begin{tabular}{|l|c|c|c|c|c|}
\hline 11.Autodenuncia & $\mathrm{x}$ & $\mathrm{V}$ & $\mathrm{V}$ & - & $\mathrm{V}$ \\
\hline $\begin{array}{l}\text { 12.Delación } \\
\text { compensada }\end{array}$ & $\mathrm{x}$ & $\mathrm{x}$ & $\mathrm{X}$ & $\mathrm{x}$ & $\mathrm{V}$ \\
\hline $\begin{array}{l}\text { 13.Salida } \\
\text { negociada en el } \\
\text { procedimiento }\end{array}$ & - & - & $\mathrm{V}$ & - & $\mathrm{V}$ \\
\hline $\begin{array}{l}\text { 14.Regulación de } \\
\text { la prueba }\end{array}$ & - & $\mathrm{V}$ & $\mathrm{V}$ & $\mathrm{V}$ & $\mathrm{V}$ \\
\hline $\begin{array}{l}\text { 15.Caducidad del } \\
\text { procedimiento }\end{array}$ & - & - & - & $\mathrm{V}$ & - \\
\hline $\begin{array}{l}\text { 16.Regulación } \\
\text { resolución } \\
\text { sancionatoria }\end{array}$ & - & - & $\mathrm{V}$ & $\mathrm{V}$ & $\mathrm{V}$ \\
\hline $\begin{array}{l}\text { 17.Regulación } \\
\text { non bis in idem }\end{array}$ & - & - & $\mathrm{V}$ & - & - \\
\hline $\begin{array}{l}\text { 18.Recursos } \\
\text { administrativos } \\
\text { especiales }\end{array}$ & - & - & $\mathrm{V}$ & $\mathrm{V}$ & $\mathrm{V}$ \\
\hline $\begin{array}{l}\text { 19.Revisión } \\
\text { judicial especial }\end{array}$ & - & $\mathrm{V}$ & $\mathrm{V}$ & $\mathrm{V}$ & \\
\hline $\begin{array}{l}\text { 20.Delimitación } \\
\text { o redundancia } \\
\text { con ilícitos } \\
\text { penales }\end{array}$ & - & $\mathrm{V}$ & $\mathrm{X}$ & $\mathrm{x}$ & $\mathrm{V}$ \\
\hline
\end{tabular}

Fuente: Elaboración propia

Así las cosas, los sectores de referencia en la última década han contribuido progresivamente a la configuración de aspectos comunes que deben concurrir para que el ejercicio de la potestad sancionatoria de la Administración sea legítima, estableciendo criterios para la determinación de la sanción, el rol de la formulación de cargos, la prueba, los regímenes de revisión del acto sancionatorio, pero también se ha ido abriendo progresivamente a la posibilidad de establecer medidas negociadas o de oportunidad al interior del procedimiento administrativo sancionador. Lo anterior ha implicado una suerte de ejercicio de homologación entre sectores por parte del legislador, que ha permitido ir construyendo, de manera inductiva, las bases de una teoría general de las sanciones administrativas en el Derecho Administrativo chileno, más allá de la configuración de potestades para el control de las atribuciones de la Administración y la garantía de derechos a favor del administrado.

Cuando en 2003 tras la sentencia del TC en el caso Gasto Electoral ${ }^{107}$, el Ejecutivo envió un proyecto de ley sobre procedimiento administrativo sancionador que finalmente archivó, su desarrollo quedó entregado a decisiones jurisprudenciales, pero también, aunque sin especial atención, a las regulaciones legales de los sectores de referencia, en que es posible identificar los que pareciera son los 20 elementos centrales del Derecho Administrativo Sancionador para el

$\overline{107}$ Tribunal Constitucional, Rol № 376, de 17 de junio de 2003. 
sistema institucional chileno, que se han ido construyendo como aportes progresivamente marginales de cada regulación sectorial, pero útiles para una discusión dogmática general.

Como se ha sostenido ${ }^{108}$, los sectores de referencia son útiles para la construcción del "proyecto de reforma del Derecho Administrativo", en donde es posible volver a rescatar la perspectiva de dirección (función posibilitadora), como un programa de conducta y no como una simple herramienta de control, y esto solo es posible en la medida que entendamos la existencia de una pluralidad de ámbitos y funciones para el Derecho Administrativo.

\section{BIBLIOGRAFÍA CITADA}

AYRES, IAN Y BRAITHWAITE, JOHN (1992): Responsive Regulation. Trascending the Deregulation Debate (Oxford, Oxford University Press).

ARANCIBIA, JAIME Y ALARCón, PABlo (2014): Sanciones Administrativas. X Jornadas de Derecho Administrativo (Santiago de Chile, Thomson Reuters).

ARÓSTICA, IVÁN (1991): "Un lustro de sanciones administrativas (1988-1992)", en: Revista de Derecho Público (№ 50 Julio/Diciembre), pp. 173-195.

BARNES VÁSQUEZ, JAVIER (2012): Innovación y reforma en el Derecho Administrativo, segunda edición (Sevilla, Global Law Press, Editorial Derecho Global).

(2011): Transformaciones (científicas) del Derecho Administrativo. Historia y retos del Derecho Administrativo (Sevilla, Global Law Press, Editorial Derecho Global).

CASSESE, SABINO (2012): "New paths for administrative law: A manifiesto", en: International Journal of Constitutional Law (Volume 10, Issue 3) pp. 603-613. Disponible en: https://doi.org/10.1093/icon/mos038 [visitado en 05 de marzo de 2019]

(2014): Derecho Administrativo: Historia y Futuro (Sevilla, Global Law Press, Editorial Derecho Global).

CORDERO QUINZACARA, EDUARDO Y ALDUNATE LIZANA, EDUARDO (2012): "Las bases constitucionales de la potestad sancionadora de la Administración", en: Revista de Derecho, Pontificia Universidad Católica de Valparaíso (XXXIX, segundo semestre), pp. 337-361.

CORDERO QUINZACARA, EDUARDO (2014): Derecho Administrativo Sancionador (Santiago de Chile, Legal Publishing, Thomson Reuters).

CORDERO VEGA, LUIS (2015): Lecciones de Derecho Administrativo, segunda edición (Santiago de Chile, Thomson Reuters).

108 PAREJO (2012), pp. 399 y 443. 
(2011): "El decaimiento del procedimiento administrativo", en: Anuario de Derecho Público (Santiago de Chile, Ediciones UDP), pp. 243-255.

(2016): "De Marín a Pierry: 20 años de la responsabilidad del Estado en la Corte Suprema", en: Ferrada, Juan Carlos, Bermúdez, Jorge y Urrutia, Osvaldo (ed.), Doctrina y enseñanza del Derecho Administrativo chileno: Estudios en Homenaje a Pedro Pierry Arrau (Valparaíso, Ediciones Universitarias de Valparaíso), pp. 393-412.

CURY URZÚA, ENRIQUe (1988): Derecho Penal. Parte general, segunda edición (Santiago de Chile, Editorial Jurídica de Chile), tomo I.

ESTEVE PARDO, JOSÉ (2014): Lecciones de Derecho Administrativo (Madrid, Marcial Pons).

FERRADA BORQUEZ, JUAN CARLOS (2005): "El sistema de Derecho Administrativo chileno: Una revisión desde una perspectiva histórica", en: Revista de Derecho Universidad de Concepción (año LXXIII, № 217-2018), pp. 99-118.

LETELIER, RAÚl (2017): "Garantías penales y sanciones administrativas", en: Revista Política Criminal (Vol. 12, № 24), pp. 622-689. nwww.politicacriminal.cl/Vol_12/n_24/Vol12N24A1.pdf [visitado en 05 de marzo de 2018]

MENDOZA ZUÑIGA, RAMIRO Y ODDO, BLANCA (2003): "Del recurso de reposición administrativo y su aplicación ante la ley especial”, en: Actualidad Jurídica (№ 8), pp. 273-292.

MONTT OYARZÚN, SANTIAGO (2011): “Autonomía y responsividad: dos expresiones de vocación juridificadora del Derecho Administrativo y sus principios fundamentales", en: De la cuétara, Juan Miguel; Martínez José Luis; Villar, Francisco José (Coord.), Derecho Administrativo y Regulación Económica (Madrid, La Ley), pp. 56-80.

NAVARRO BELTRÁN, ENRIQUE (2014): "La potestad sancionadora administrativa y la jurisprudencia del Tribunal Constitucional”, en: Arancibia Mattar, Jaime y Alarcón Jaña, Pablo (coords.), Sanciones administrativas, $X$ Jornadas de Derecho Administrativo (Santiago de Chile, Legal Publishing, Thomson Reuters), pp. 17-38.

NIETO GARCíA, ALEJANDRO (2005): Derecho Administrativo Sancionador, cuarta edición totalmente reformada (Madrid, Tecnos).

PANTOJA BAUZÁ, ROLANDO (1986): Bases Generales de la Administración del Estado (Santiago de Chile, Ediar Conosur Ltda).

Jurídica).

(1994): Derecho Administrativo. Clasicismo y modernidad (Santiago de Chile, Editorial

REBOLLO PUIG, MANUEL Y VERA JURADO, DIEGO (2016): Derecho Administrativo. Conceptos fundamentales, fuentes y organización, segunda edición (Madrid, Tecnos), tomo I. 
RODRÍGUEZ COLLAO, LUIS (1987): "Bases para distinguir entre infracciones criminales y administrativas", en: Revista de Derecho de la Pontificia Universidad Católica de Valparaíso ( $N^{\circ} 11$ ), pp. 117-163.

ROSE-ACKERMAN, SUSAN Y LINDSETH, PETER (2010): “Comparative administrative law: an introduction”, en: Rose-Ackerman, Susan y Lindseth, Peter (ed.), Comparative Administrative Law (Cheltenham, Edward Elgar), pp. 1-20.

SCHMIDT-ASSMANN, EBERHARD (2003): La teoría general del Derecho Administrativo como sistema (Traducc. Mariano Bacigalupo, Javier Barnés, Javier García Luengo, Ricardo García Macho, Alejandro Huergo, José María Rodríguez de Santiago, Blanca Rodríguez Ruiz, Germán Valencia, Francisco Velasco, Madrid, Marcial Pons).

(2012): "Cuestiones fundamentales sobre la reforma de la Teoría General del Derecho Administrativo", en: Barnes, Javier (coordinador), Innovación y reforma en el Derecho Administrativo, segunda edición (Sevilla, Global Law Press, Editorial Derecho Global), pp. 21-140.

SEERDEN, RENÉ (2018): Comparative Administrative Law. Administrative law of the European Union, Its Members States and the United States, Fourth Edition (United Kingdom, Intersentia).

SILVA CIMMA, ENRIQUE (2009): Derecho Administrativo chileno y comparado. Introducción y fuentes, quinta edición (Santiago de Chile, Editorial Jurídica de Chile).

SOTO KLOSS, EDUARDO (2012): Derecho Administrativo, Temas Fundamentales, tercera edición (Santiago de Chile, Thomson Reuters).

SUNSTEIN, CASS (1993): After the Rights Revolution. Reconceiving the Regulatory State (Cambridge, Harvard University Press).

(1996): Derecho Administrativo. Bases Fundamentales (Santiago de Chile, Editorial Jurídica de Chile), tomo I.

VALDIVIA, JOSÉ Y BLACKE, TOMÁS (2015): “El decaimiento del procedimiento administrativo sancionador ante el derecho administrativo", en: Estudios Públicos (138, otoño 2015), pp. 93-135.

VEDEL, GEORGES (1980): Derecho Administrativo, sexta edición (Traducc. Juan Rincón, Madrid, Aguilar).

VelASCO, FRANCISCO (2014): Derecho Público más Derecho Privado (Madrid, Marcial Pons).

WAHL, RAINER (2013): Los últimos cincuenta años de Derecho Administrativo Alemán (Traducc. José Carlos Mardomingo, Madrid, Marcial Pons).

\section{JURISPRUDENCIA CITADA}

MODIFICA LEY № 4.601, LEY DE CAZA (1996): Tribunal Constitucional 26 de agosto de 1996, Rol № 244 (control de constitucionalidad). 
PROYECTO DE LEY SOBRE TRANSPARENCIA, LÍMITE Y CONTROL DEL GASTO ELECTORAL (2003): Tribunal Constitucional 17 de junio de 2003, Rol N³76 (control de constitucionalidad).

DICTAMEN N¹4.571, 22 de marzo de 2005.

ARAUCO GENERACIÓN EN CONTRA DE SEC (2005): Corte Suprema 8 de noviembre de 2005, Rol № 4.4042005 (apelación reclamación).

IBEROAMERICANA DE ENERGÍA IBENER S.A CON SUPERINTENDENCIA DE ELECTRICIDAD Y COMBUSTIBLES (2006): Tribunal Constitucional 13 de abril de 2006, Rol № 480 (requerimiento de inaplicabilidad artículo. 81 № 1, DFL № 1, de 1982 del Ministerio de Minería).

COMPAÑÍA ELÉCTRICA SAN ISIDRO S.A CON SUPERINTENDENCIA DE ELECTRICIDAD Y COMBUSTIBLES (2006): Tribunal Constitucional 8 de agosto de 2006, Rol № 479 (requerimiento de inaplicabilidad por inconstitucionalidad artículo 15 de la Ley № 18.410).

PFEIFER FRENZ CON INSTITUTO DE SALUD PÚBLICA (2007): Tribunal Constitucional 3 de enero de 2008, Rol $N^{\circ} 792$ (Requerimiento de inaplicabilidad respecto de la segunda frase del inciso primero del artículo 171 del Código Sanitario).

FM SEGURIDAD S.A. CON DIRECCIÓN REGIONAL DEL TRABAJO (2007): Tribunal Constitucional 1 de julio de 2008, Rol N ${ }^{\circ} 946$ (Requerimiento de inaplicabilidad respecto del inciso tercero del artículo 474 del Código del Trabajo).

MARÍA ANGELICA SÁNCHEZ VOGEL Y OTROS (2009): Tribunal Constitucional 21 de octubre de 2010, Rol $\mathrm{N}^{\circ} 1518$ (requerimiento de inaplicabilidad por inconstitucionalidad respecto del artículo 169 del Código Sanitario).

PROYECTO DE LEY QUE REGULA EL CIERRE DE FAENAS E INSTALACIONES MINERAS (2011): Tribunal Constitucional 18 de octubre de 2011, Rol N²036 (control de constitucionalidad).

DICTAMEN N60.341, 23 de septiembre de 2013.

INSTITUTO DE PREVISIÓN SOCIAL CON BRAVO HERRERA, JULIA (2013): Tribunal Constitucional 17 de octubre de 2013, Rol N²452 (Requerimiento de inaplicabilidad por inconstitucionalidad respecto del artículo $8^{\circ}$ de la Ley $\left.N^{\circ} 17.322\right)$.

INDUSTRIA FRIGORÍFICA SIMUNOVIC CON COMISIÓN DE EVALUACIÓN AMBIENTAL DE MAGALLANES Y ANTÁRTICA CHILENA (2013): Corte Suprema 18 de agosto de 2014, Rol №14.432-2013 (casación en el fondo).

MOTTA CAMP ALDO CON SUPERINTENDENCIA DE VALORES Y SEGUROS (2014): Tribunal Constitucional 30 de octubre de 2014, Rol N²682 (Requerimiento de inaplicabilidad por inconstitucionalidad respecto del precepto legal contenido en el inciso segundo del artículo 35 de la Ley $\mathrm{N}^{\circ}{ }^{19.880}$ ).

INSTITUTO DE NORMALIZACIÓN PREVISIONAL CON OLIVOS (2015): Tribunal Constitucional 24 de diciembre de 2015, Rol N²853 (Requerimiento de inaplicabilidad por inconstitucionalidad respecto del inciso primero del artículo 8 de la Ley $\mathrm{N}^{\circ} 17.322$ ). 
FNE CONTRA CMPC TISSUE S.A. Y OTRA (2015): Tribunal Constitucional 8 de enero de 2016, Rol №2934 (Contienda de competencia suscitada entre el Tribunal de Defensa de la Libre Competencia y la Fiscalía Regional Metropolitana Sur del Ministerio Público).

ESVAL S.A CON GOBERNACIÓN MARÍTIMA DE VALPARAíso (2015): Tribunal Constitucional 12 de mayo de 2016, Rol № 2784 (requerimiento de inaplicabilidad artículo 3, letra i) y I) de la Ley de Orgánica de la Dirección de Territorio Marítimo y arts. 149, 150 y 151 del DL № 2222, que establece la Ley de Navegación).

GUZMÁN LYON, ROBERTO CON SUPERINTENDENCIA DE VALORES Y SEGUROS (2015): Tribunal Constitucional 29 de septiembre de 2016, Rol № 2922, (Requerimiento de inaplicabilidad por inconstitucionalidad respecto del artículo 29 del $\mathrm{DL} \mathrm{N}^{\circ} 3.538$, de 1980).

ALCALDE DE ALGARROBO CON CONSEJO PARA LA TRANSPARENCIA (2015): Tribunal constitucional 6 de diciembre de 2016, Rol №2895 (Requerimiento de Inaplicabilidad por inconstitucionalidad respecto del artículo 28, inciso segundo, de la Ley º20.285, sobre Acceso a la Información Pública).

EMPRESA NACIONAL DE ELECTRICIDAD S.A. CON SUPERINTENDENCIA DEL MEDIO AMBIENTE (2016): Corte Suprema 13 de diciembre de 2016, Rol N¹7.736-2016 (casación en la forma y fondo).

PAMPA CAMARONES S.A. CON SUPERINTENDENTE DEL MEDIO AMBIENTE (2016): Corte Suprema 1 de marzo de 2017, Rol N41815-2016 (casación en la forma y fondo).

TORO PAPAPIETRO LUIS MATÍAS DONATO / ISAPRE CONSALUD S.A. (2016): Corte Suprema 9 de mayo de 2017, rol 62.128-2016 (queja).

SERVICIO DE IMPUESTOS INTERNOS CON CONSEJO PARA LA TRANSPARENCIA (2016): Tribunal Constitucional 13 de junio de 2017, rol №2997 (Requerimiento de inaplicabilidad por inconstitucionalidad respecto del artículo 28, inciso segundo, de la Ley N²0.285, sobre Acceso a la Información Pública).

BULNES Y OTRO CON SUPERINTENDENCIA DE VALORES Y SEGUROS (2016): Tribunal Constitucional 14 de noviembre de 2017, Rol N³014 (Requerimiento de inaplicabilidad por inconstitucionalidad respecto del inciso primero del artículo 29 del D.L. N³.538, de 1980, Ley Orgánica de la Superintendencia de Valores y Seguros).

PONCE CON SUPERINTENDENCIA DE VALORES Y SEGUROS (2016): Tribunal Constitucional 24 de mayo de 2018, Rol № 3236 (Requerimiento de inaplicabilidad por inconstitucionalidad respecto del inciso primero del artículo 29 del D.L. N³.538, de 1980, Ley Orgánica de la Superintendencia de Valores y Seguros).

EMPRESA PORTUARIA Y OTROS SERVICIOS CONEXOS / SECRETARÍA REGIONAL MINISTERIAL DE SALUD DE ANTOFAGASTA (2017): Corte Suprema 8 de junio de 2017, Rol N7.112-2017 (casación en el fondo).

LARRAÍN VIAL S.A. CORREDORES DE BOLSA CON SUPERINTENDENCIA DE VALORES Y SEGUROS (2017): Tribunal Constitucional 7 de mayo de 2018, Rol N³575 (Requerimiento de inaplicabilidad por inconstitucionalidad respecto del inciso primero del artículo 29 del D.L. N³.538, de 1980, Ley Orgánica de la Superintendencia de Valores y Seguros). 
LE BLANC MATTHAEI, ALBERTO CON SUPERINTENDENCIA DE VALORES Y SEGUROS (2017): Tribunal Constitucional 7 de mayo de 2018, Rol $\mathrm{N}^{\circ} 3542$ (Requerimiento de inaplicabilidad por inconstitucionalidad respecto del inciso primero del artículo 29 del D.L. N³.538, de 1980, Ley Orgánica de la Superintendencia de Valores y Seguros).

CONTESSE CON SUPERINTENDENCIA DE VALORES Y SEGUROS (2017): Tribunal Constitucional de 24 de enero de 2019, Rol N³932 (Requerimiento de inaplicabilidad por inconstitucionalidad respecto del inciso primero del artículo 29 del D.L. N³.538, de 1980, Ley Orgánica de la Superintendencia de Valores y Seguros).

PROYECTO DE LEY QUE MODIFICA LEY N 19.496, SOBRE PROTECCIÓN DE LOS DERECHOS DE LOS CONSUMIDORES (2018): Tribunal Constitucional 18 de enero del 2018, Rol № 4012 (control de constitucionalidad).

PROYECTO DE LEY SOBRE EDUCACIÓN SUPERIOR (2018): Tribunal Constitucional 26 de abril de 2018, Rol № 4317 (control de constitucionalidad).

MOTTA CON SUPERINTENDENCIA DE VALORES Y SEGUROS (2018): Tribunal Constitucional 24 de enero de 2019, Rol $N^{\circ} 4230$ (Requerimiento de inaplicabilidad por inconstitucionalidad respecto del inciso primero del artículo 29 del D.L. №3.538, de 1980, Ley Orgánica de la Superintendencia de Valores y Seguros).

\section{NORMAS JURÍDICAS CITADAS}

DECRETO CON FUERZA DE LEY № 725, CóDIGO SANITARIO. Diario Oficial, 31 de enero de 1968.

LEY № 18.575, BASES GENERALES DE LA ADMINISTRACIÓN DEL ESTADO. Diario Oficial, 05 de diciembre de 1986.

LEY № 18.834, ESTATUTO ADMINISTRATIVO. Diario Oficial, 23 de septiembre de 1989.

LEY № 19.880, Establece bases de los procedimientos administrativos que rigen los actos de los órganos de la administración del Estado. Diario Oficial, 29 de mayo de 2003.

LEY № 19.884, Sobre transparencia, límite y control del gasto electoral. Diario Oficial, 5 de agosto de 2003.

LEY № 19.886, Ley sobre contratos administrativos de suministros y prestación de servicios. Diario Oficial, 30 de julio de 2003.

LEY № 19.911, Crea el Tribunal de Defensa de la Libre Competencia. Diario Oficial, 14 de noviembre de 2003.

LEY № 19.913, Crea la Unidad de Análisis Financiero y modifica diversas disposiciones en materia de lavado y blanqueo de activos. Diario Oficial, 18 de diciembre de 2003.

LEY $N^{\circ} 19.963$, Modifica la ley $\mathrm{N}^{\circ} 19884$, sobre transparencia, límite y control del gasto electoral, estableciendo sanciones y el procedimiento para su aplicación. Diario Oficial, 24 de agosto de 2004. 
LEY № 19.974, Sobre el sistema de inteligencia del Estado y crea la Agencia Nacional de Inteligencia. Diario Oficial, 2 de octubre de 2004.

LEY № 19.995, Establece las bases generales para la autorización, funcionamiento y fiscalización de casinos de juego. Diario Oficial, 7 de enero de 2005.

LEY № 20.004, Modifica ley № 18.175, en materia de fortalecimiento de la transparencia en la administración privada de las quiebras, fortalecimiento de la labor de los síndicos y de la Superintendencia de Quiebras. Diario Oficial, 8 de marzo de 2005.

LEY № 20.053, Modifica la ley N¹9.884, sobre transparencia, límite y control del gasto electoral. Diario Oficial, 6 de septiembre de 2005.

LEY № 20.285, Sobre acceso a la información pública. Diario Oficial, del 20 de agosto de 2008.

LEY N²0.322, Fortalece y perfecciona la jurisdicción tributaria y aduanera. Diario Oficial, 27 de enero del 2009.

LEY № 20.378, Crea un subsidio nacional para el transporte público remunerado de pasajeros. Diario Oficial, 5 de septiembre de 2009.

LEY № 20.416, Fija normas especiales para las empresas de menor tamaño. Diario Oficial, 3 de febrero de 2010.

LEY № 20.417, Crea el Ministerio, el Servicio de Evaluación Ambiental y la Superintendencia del Medio Ambiente. Diario Oficial, 26 de enero de 2010.

LEY № 20.529, Sistema nacional de aseguramiento de la calidad de la educación parvularia, básica y media y su fiscalización. Diario Oficial, 27 de agosto del 2011.

LEY № 21.000, Crea la Comisión para el Mercado Financiero. Diario Oficial, del 23 de febrero de 2017.

LEY № 21.039, Perfecciona la justicia tributaria y aduanera. Diario Oficial, 20 de octubre de 2017.

LEY № 21.091, Sobre educación superior. Diario Oficial, 29 de mayo de 2018.

"PROYECTO DE LEY QUE ESTABLECE LAS BASES DE LOS PROCEDIMIENTOS ADMINISTRATIVOS SANCIONATORIOS Y MODIFICA LA LEY № 19.884, SOBRE TRANSPARENCIA, LÍMITE Y CONTROL DEL GASTO ELECTORAL". Boletín №3.47506. 